\title{
Arachnoid Membranes: Crawling Back into Radiologic Consciousness
}

\author{
(D) S. Lu, (D) A. Brusic, and (DF. Gaillard
}

\section{ABSTRACT}

SUMMARY: The arachnoid membranes are projections of connective tissue in the subarachnoid space that connect the arachnoid mater to the pia mater. These are underappreciated and largely unrecognized by most neuroradiologists despite being found to be increasingly important in the pathogenesis, imaging, and treatment of communicating hydrocephalus. This review aims to provide neuroradiologists with an overview of the history, embryology, histology, anatomy, and normal imaging appearance of these membranes, as well as some examples of their clinical importance.

ABBREVIATIONS: ETV = endoscopic third ventriculostomy; $L M=$ Liliequist membrane

$\mathbf{T}$ he subarachnoid space is traversed by projections of connective tissue covered in leptomeningeal cells that connect the arachnoid mater to the pia mater. These have a variety of morphologies ranging from thin cylinders (referred to as "pillars," "rods," or "trabeculae") to more elongated flattened structures (referred to as "septa"). ${ }^{1}$ In some areas, these septa are particularly extensive, forming semicontinuous sheets referred to as "arachnoid membranes" (also known as "subarachnoid trabecular membranes" or "inner arachnoid membranes"). The subarachnoid cisterns, typically named according to the brain structures they abut, are often separated from each other by these membranes, which, in turn, determine the flow of CSF from one cistern to the next.

The importance of arachnoid membranes is well-known within the neurosurgery community because these membranes, together with the subarachnoid cisterns, provide natural avenues for dissection during surgery. ${ }^{2}$ In contrast, current neuroradiologists and modern radiology literature are less familiar with their existence and anatomy despite their impact on everyday clinical imaging and their potential importance in understanding a variety of conditions characterized by abnormal CSF flow.

Received May 2, 2021; accepted after revision July 29.

From the Department of Radiology (S.L., A.B., F.G.), Royal Melbourne Hospital, Parkville, Victoria, Australia; and Faculty of Medicine, Dentistry, and Health Sciences (F.G.), University of Melbourne, Parkville, Victoria, Australia.

Please address correspondence to Shisheng Lu, MBBS, Department of Radiology, Royal Melbourne Hospital, 300 Grattan St, Parkville VIC 3050, Australia; e-mail: lushisheng@gmail.com

- Indicates open access to non-subscribers at www.ajnr.org

Indicates article with online supplemental data.

http://dx.doi.org/10.3174/ajnr.A7309
This review seeks to provide neuroradiologists with an overview of the histology, embryology, anatomy, and normal imaging appearance of these membranes, as well as some examples of their clinical importance.

\section{History}

While the dura and pia mater were described by Galen in the second century $\mathrm{AD},{ }^{3}$ the intervening arachnoid mater was not described until the 17th century. Gerardus Blasius (1626-1692) was the first to describe and name the arachnoid layer of the meninges in 1664, naming it in recognition of its cobweb-like traversing membranes and trabeculations, and Frederick Ruysch (1638-1731) confirmed that the arachnoid mater comprised a complete layer surrounding the brain. ${ }^{4,5}$ In the 1690 s, Humphrey Ridley (1653-1708) wrote about the concept of the subarachnoid cistern, describing the cerebellomedullary, quadrigeminal, and olfactory cisterns. ${ }^{5}$

It was not until the 19th century that the role of the arachnoid membranes in influencing the flow of CSF was recognized. In 1842, Francois Magendie (of foramen of Magendie fame; 17831855) demonstrated that CSF in the ventricles freely communicates with the subarachnoid space, and in 1869, Axel Key (1832-1901) and Magnus Retzius (1842-1919) published detailed drawings of the subarachnoid cisterns and the arachnoid trabeculations and, with a series of experiments using injected dye, demonstrated the free communication of CSF through the fenestrations in the arachnoid. $^{6}$

The importance of the arachnoid membranes in neurosurgery was recognized by Gazi Yasargil (1925), one of the pioneers of microneurosurgery, who introduced the technique of moving from 1 cistern to another during neurosurgical procedures by 

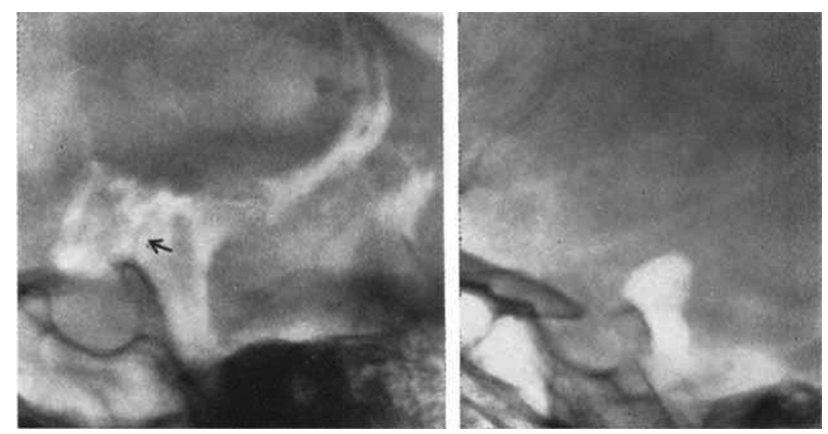

FIG 1. Lateral pneumoencephalogram demonstrating the LM (left) and the air column arrested in the interpeduncular cistern against the LM (right). Arrow in the left image points to the LM (left). Reproduced with permission from Liliequist. ${ }^{8}$ Copyright (1956) SAGE Publications.

dividing the arachnoid membranes that separate the cisterns. ${ }^{2}$ Yasargil also noted that the arachnoid membranes were often porous with various-sized openings and that the openings could become plugged and obliterated after subarachnoid hemorrhage.

The radiologic importance of the anatomy of the subarachnoid space dates back to the very earliest days of imaging. In 1919, a mere 24 years after Wilhelm Röentgen took the first-ever $\mathrm{x}$-ray image (of the hand of his wife on December 22, 1895), Walter Dandy developed pneumoencephalography. At the time a novel technique, this aided the diagnosis and localization of intracranial tumors and was widely used until the 1970s. Pneumoencephalography was an invasive and unpleasant procedure, involving injecting air either directly into the ventricles or into the lumbar subarachnoid space and maneuvering the patient to allow the air to float into the intracranial subarachnoid space and ventricles. ${ }^{7}$ This procedure caused the CSF to be displaced, creating greater contrast between the brain parenchyma and the ventricles, sulci, cisterns, and recesses on cranial radiography. Thus, distortion in the shape or alteration in the location of normal structures could be identified, and the presence of a tumor, inferred. Incidentally, it was recognized that air tended to accumulate within predictable areas of the subarachnoid space, indirectly allowing imaging of the arachnoid membranes.

It was only in 1956 that a Swedish neuroradiologist, Bengt Liliequist $^{8}$ (1923-2008), having noted that during pneumoencephalography air often paused in the interpeduncular cistern before gradually filling the chiasmatic cistern, first described the imaging appearance of the membrane bearing his name. ${ }^{9}$ The Liliequist membrane (LM) could often be seen on a lateral pneumoencephalogram as a fine line with a convexity forward, extending from the tip of the dorsum of the sella to the anterior edge of the mammillary bodies (Fig 1).

As pneumoencephalography fell out of favor in preference to the newly developed and noninvasive cross-sectional modalities of $\mathrm{CT}$ and MR imaging, so too did routine radiologic visualization of the arachnoid membranes, and, with time, their anatomy largely receded from our collective radiologic memory.

Fortunately, with the advent of higher-field-strength and higher-resolution MR imaging, we are now in a position to once more image these important structures.

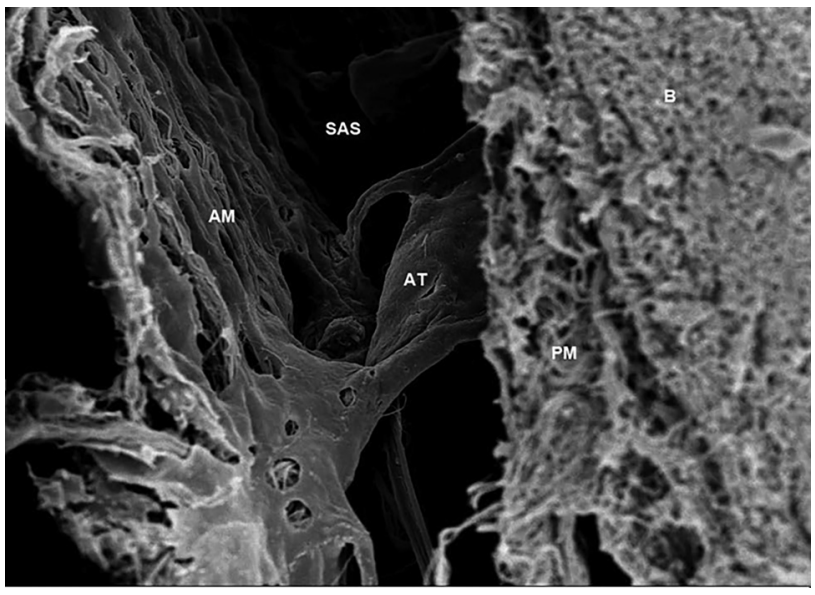

FIG 2. Scanning electron microscope image obtained in the brain of a Sprague-Dawley rat, showing the arachnoid trabeculae (AT) located in the subarachnoid space (SAS) and connected to the arachnoid mater (AM) and pia mater (PM) just next to the brain (B). The parameters are the following: magnification $=2.50 \mathrm{~K} \mathrm{X}$; high current $=$ off; electron high tension $=5.00 \mathrm{kV}$; signal $A=\operatorname{InLens;}$ scan speed $=7$; focus $=4.6 \mathrm{~mm}$; stage at $Z=45.724 \mathrm{~mm}$; system vacuum $=2.51 \mathrm{e}-006$ mbar; tilt angle $=0.0^{\circ}$; working distance $=4.6 \mathrm{~mm}$. Used with permission from Saboori. Copyright (2020) Wiley. ${ }^{48}$

\section{Embryology}

The embryologic development of the subarachnoid space and its membranes occurs in 2 phases. The first is the development of a primitive space-holding mesenchymal layer known as the meninx primitiva, or primitive subarachnoid space, and the second is the development and expansion of lacunae, causing compaction of the mesenchyme. ${ }^{10}$

In the first phase, shortly after the closure of the neural tube at approximately days 10-13 postconception (fourth week of pregnancy), mesenchymal cells move from the developing cervical spine into the space formed between the embryonic epithelium and neuroepithelium of the telencephalon. ${ }^{10,11}$ At this stage, the meninx primitiva consists of a gel-like layer of glycosaminoglycans (chains of repeating disaccharides) with widely spaced pluripotent stellate mesenchymal cells and a vascular plexus. ${ }^{12}$

In the second phase, random fluid-filled cavities or lacunae begin to form in this gel-like meninx primitiva, gradually enlarging and pushing the mesenchymal cells apart. Where the walls of the cavities meet, the cells become compacted, forming membranes. At this stage, primary or congenital arachnoid cysts may form as a result of duplication of the arachnoid membranes or failure of meningeal fusion. ${ }^{13,14}$ On the inner and outer aspects of the meninx primitiva, the mesenchymal cells begin to specialize, forming the arachnoid and pia mater; this process is usually complete by day $17 .{ }^{10,15}$ The arachnoid membranes are, therefore, the remaining trabeculated structures joining the 2 inner layers of the meninges.

\section{Histology}

Arachnoid septa, trabeculae, and membranes are projections that extend from the arachnoid mater to the pia mater (Fig 2). Arachnoid trabeculae are composed of collagen bundles coated by leptomeningeal cells, which are joined by desmosomes and 
gap junctions. ${ }^{16}$ Small vessels within the subarachnoid space are enclosed within the trabeculae, and larger vessels are coated by leptomeningeal cells, which are continuous with cells in the trabeculae. Where the trabeculae join the pia mater, the cellular layers of the trabeculae become continuous with the outer layer of the pia mater.

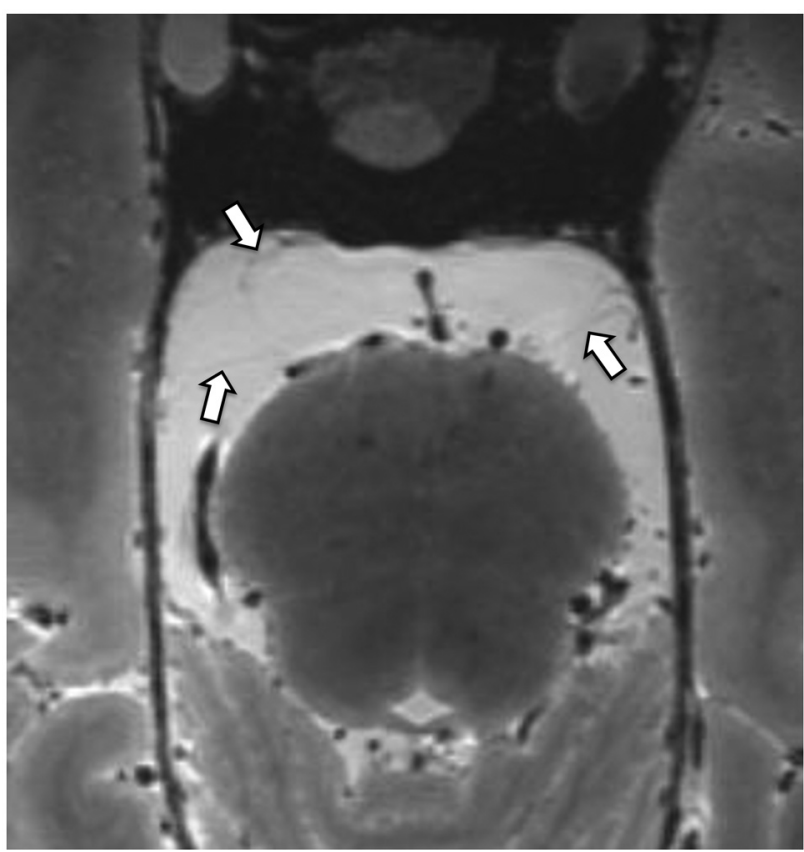

FIG 3. Axial reformat of a high-resolution $T 2$-weighted sequence of a cadaveric head on a 7T MR imaging scanner. ${ }^{49}$ The arachnoid membranes (arrows) in the prepontine cistern are very thin and barely perceptible. Acknowledgment: The authors acknowledge the facilities and scientific and technical assistance of the National Imaging Facility, a National Collaborative Research Infrastructure Strategy capability, at the Melbourne Brain Center Imaging Unit, Department of Radiology, University of Melbourne. Financial support was provided via the "See It, Slice It, Learn It" project funded by a University of Melbourne internal grant. ${ }^{49}$
In certain areas, very dense networks of semicontinuous trabeculae are present and have the appearance and qualities of true membranes. ${ }^{17}$ These membranes divide the subarachnoid space into individual cisterns and provide support for the neurovasculature that passes through them. ${ }^{17}$ These arachnoid membranes vary greatly in macroscopic appearance: They can be transparent or semitransparent, membranous or reticulated, porous or intact, and thin or thick, and the same anatomic membrane can appear different in different specimens. ${ }^{5}$

\section{Imaging}

The arachnoid membranes were first seen radiologically on pneumoencephalography. As CT and MR imaging became established imaging modalities, however, pneumoencephalography became effectively obsolete in the 1970 s. ${ }^{18}$ Unfortunately, due to the limitations of spatial resolution of early CT and MR imaging, it was also no longer possible to visualize the arachnoid membranes. It has not been until recently with the development of high-resolution MR imaging techniques, such as the true fast imaging with steadystate precession and CISS (Siemens), FIESTA and FIESTA-C (GE Healthcare), Balanced fast field echo (Philips Healthcare), balanced SARGE and phase-balanced SARGE (Hitachi), and True steadystate free precession (Toshiba), that some of the arachnoid membranes are again sometimes visible on routine imaging.

Normal arachnoid membranes, when visible, appear as thin T2-hypointense lines traversing the CSF in the subarachnoid space. Because the arachnoid membranes are very thin, especially in the absence of disease, most normal membranes remain elusive and difficult to visualize, even with high-resolution high-fieldstrength scans (Fig 3). Instead, the presence of the arachnoid membranes can often be inferred on most routine scans from the containment and separation of CSF flow voids and artifacts in neighboring subarachnoid cisterns (Fig 4). In contrast, in the presence of subarachnoid hemorrhage, inflammation, or tumor, arachnoid membranes may become thickened, facilitating easier identification, typically on dedicated high-resolution imaging (Fig 5).
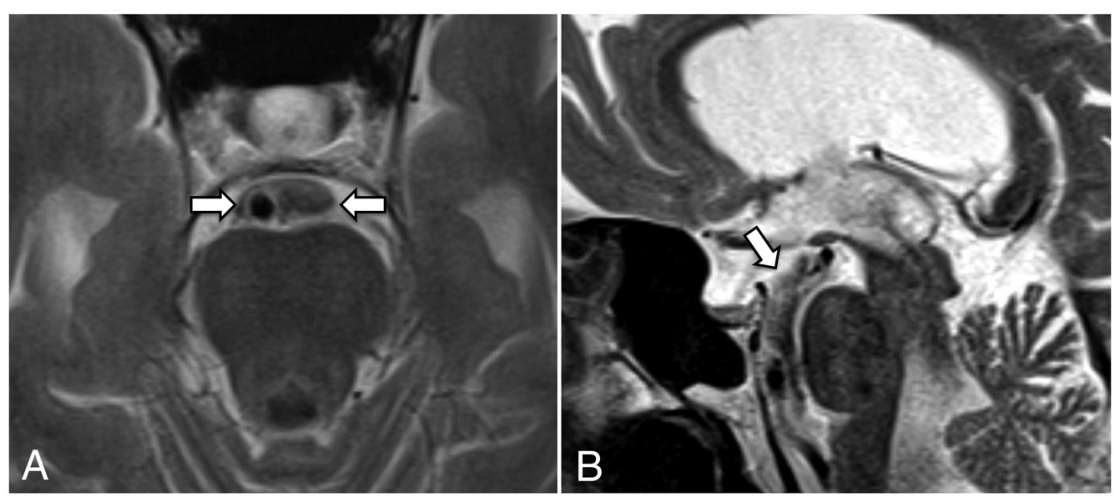

FIG 4. A, T2-weighted axial image (section thickness $=3 \mathrm{~mm}$ ) shows a prominent CSF flow void around the basilar artery confined to the prepontine cistern. The lateral margins of the flow void (arrows) are likely due to the anterior pontine membranes. B, T2-weighted midline sagittal image (section thickness $=3 \mathrm{~mm}$ ) demonstrates a CSF flow void tracking along the prepontine and interpeduncular cisterns, with an abrupt change in signal superiorly at the expected location of the diencephalic leaf of the LM (arrow).

\section{Anatomy}

Similar to the subarachnoid cisterns, the arachnoid membranes are generally named according to their relationship to the adjacent brain, with the exception of the eponymously named LM. The microsurgical anatomy of multiple arachnoid membranes has been welldescribed in the neuroanatomy literature, ${ }^{17,19-31}$ and these are summarized in the Online Supplemental Data. ${ }^{5}$ The list is rather extensive, and identification of these membranes is difficult even with high-resolution MR imaging techniques. Furthermore, the exact attachments and boundaries of various membranes are variably described, presumably representing variability not only in description but also in true 
anatomy. Nonetheless, it is worthwhile discussing the anatomy of the arachnoid membranes associated with the interpeduncular and prepontine cisterns (Figs 6 and 7) because abnormally thickened
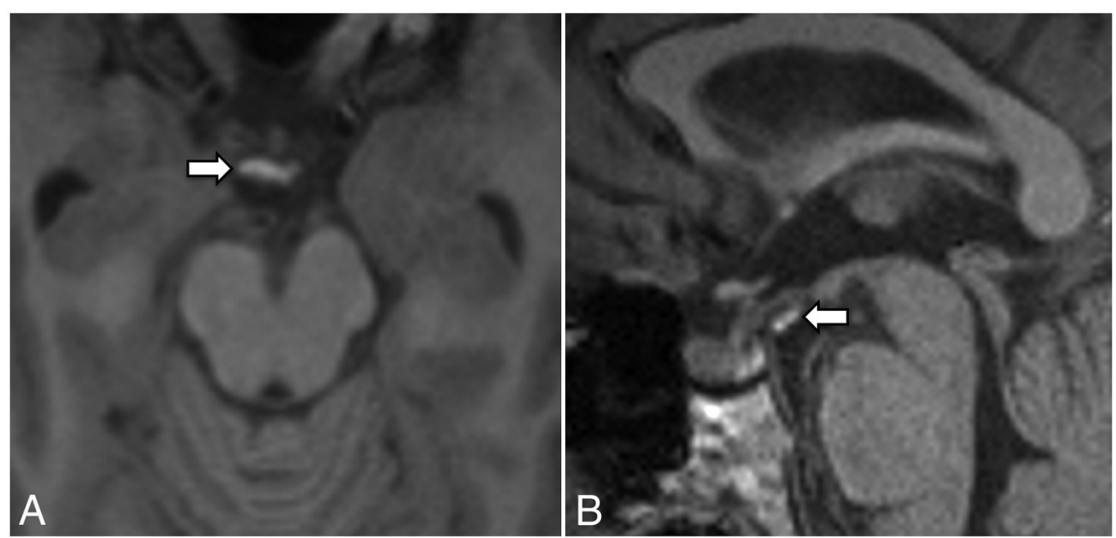

FIG 5. Axial $(A)$ and sagittal $(B)$ TI MPRAGE images of a patient with subarachnoid hemorrhage show a T7-hyperintense blood product attached to the LM (arrows). The MR imaging examination was performed on day 8 postpresentation. membranes are commonly identified in these cisterns in some patients with communicating hydrocephalus. ${ }^{32,33}$

The interpeduncular cistern is bounded by the midbrain posteriorly and the 2 leaves of the LM anterior-superiorly and anterior-inferiorly. The LM (Figs 8 and 9) arises from the posterior clinoid processes and dorsum sellae and extends posterior-superiorly, separating into 2 sheets. ${ }^{19}$

One sheet, known as the diencephalic leaf, extends posterior-superiorly and attaches to the diencephalon at or anterior to the mammillary bodies. It is fairly complete anteriorly, thus impeding the spread of air on pneumoencephalography, but it is less complete posteriorly near its attachment. $^{26}$ The diencephalic leaf thus separates the chiasmatic cistern from the interpeduncular cistern. The other sheet, known as the mesencephalic
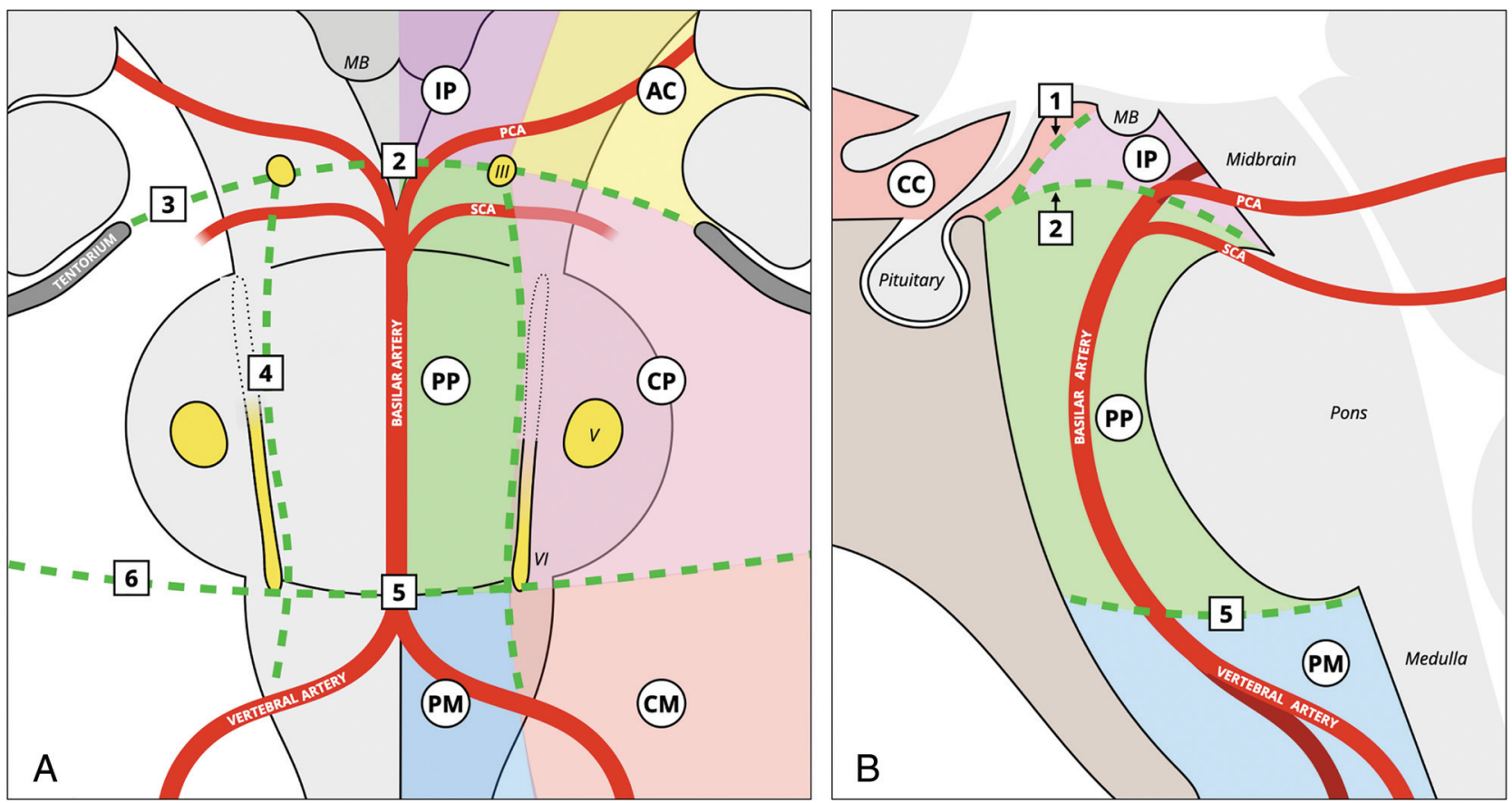

FIG 6. Illustration of arachnoid membranes in relation to the neurovascular structures in the interpeduncular and prepontine cisterns in the coronal $(A)$ and sagittal $(B)$ planes. The LM runs posterior-superiorly from the dorsum sellae and posterior clinical process. Its diencephalic leaf continues to run posterior-superiorly and attaches to or just anterior to the mammillary bodies, separating the interpeduncular cistern from the chiasmatic cistern. The mesencephalic leaf of the LM extends posteriorly and is divided by the oculomotor nerves into medial and lateral parts. The medial part, attached to the distal basilar artery or the pontomesencephalic junction, separates the interpeduncular cistern from the prepontine cistern. The lateral parts, attached to the tentorium and the mesial temporal lobes, separate the ambient cisterns from the cerebellopontine cisterns. The anterior pontine membranes run on either side of the basilar artery and are medial to the abducens nerves, separating the prepontine cistern from the cerebellopontine cisterns. The medial pontomedullary membrane, located in the midline portion of the pontomedullary sulcus, separates the prepontine cistern from the premedullary cistern. The lateral pontomedullary membranes, located in the lateral portion of the pontomedullary sulcus, separate the cerebellomedullary cisterns from the cerebellopontine cisterns. The numbers represent the following: 1) diencephalic leaf of the LM; 2) medial attachment of the mesencephalic leaf of the LM; 3) lateral attachment of the mesencephalic leaf; 4) anterior pontine membrane; 5) medial pontomedullary membrane; 6) lateral pontomedullary membrane. III indicates the oculomotor nerve; $\mathrm{V}$, trigeminal nerve; $\mathrm{VI}$, abducens nerve; $\mathrm{AC}$, ambient cisterns; $\mathrm{CC}$, chiasmatic cistern; $\mathrm{CM}$, cerebellomedullary cistern; $\mathrm{CP}$, cerebellopontine cistern; IP, interpeduncular cistern; MB, mammillary bodies; PCA, posterior cerebral artery; PM, premedullary cistern; PP, prepontine cistern; SCA, superior cerebellar artery. Reproduced with permission from Frank Gaillard and Radiopaedia.org. Copyright (2021) Radiopaedia. 

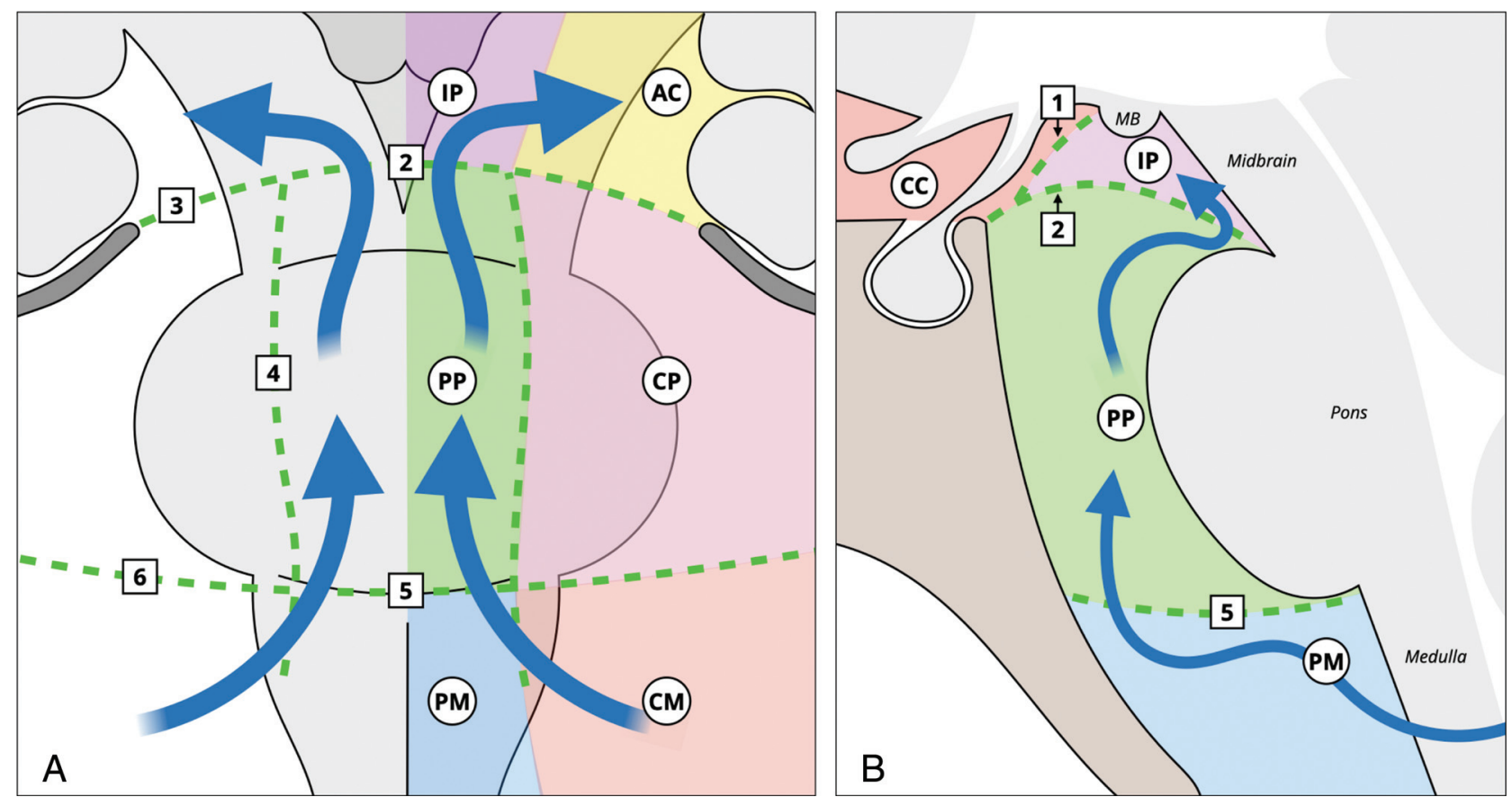

FIG 7. Illustration of arachnoid membranes and the CSF flow at the level of the interpeduncular and prepontine cisterns in the coronal (A) and sagittal (B) planes. The CSF enters the prepontine cistern from the cerebellomedullary and the premedullary cisterns. It runs superiorly within the prepontine cistern and enters the interpeduncular cistern. From there, the CSF can flow laterally and anteriorly into the chiasmatic cistern or posteriorly into the ambient cisterns. The numbers represent the following: 1) diencephalic leaf of the LM; 2) medial attachment of the mesencephalic leaf of the LM; 3) lateral attachment of the mesencephalic leaf; 4) anterior pontine membrane; 5) medial pontomedullary membrane; 6) lateral pontomedullary membrane. AC indicates ambient cisterns; CC, chiasmatic cistern; CM, cerebellomedullary cistern; CP, cerebellopontine cistern; IP, interpeduncular cistern; MB, mammillary bodies; PM, premedullary cistern; PP, prepontine cistern. Reproduced with permission from Frank Gaillard and Radiopaedia.org. Copyright (2021) Radiopaedia.

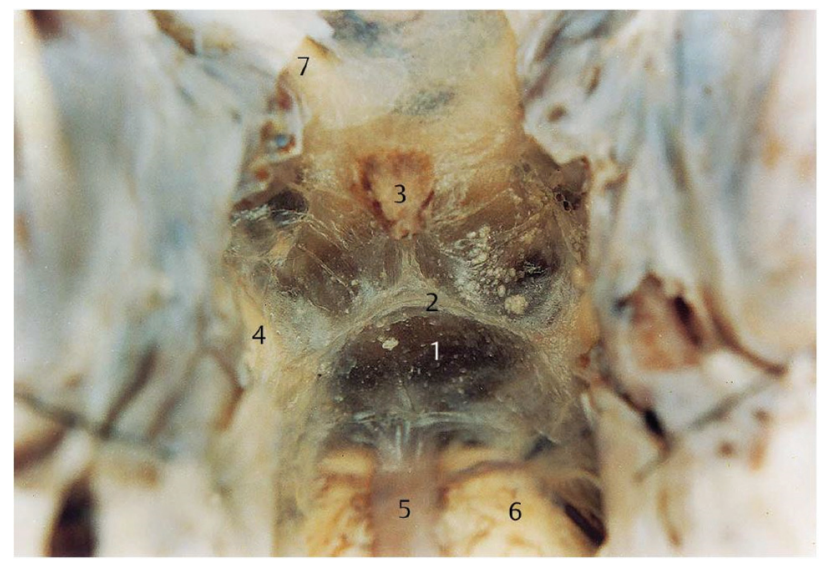

FIG 8. Microsurgical photograph of the LM taken in an adult human cadaveric brain in an oblique coronal view (about $45^{\circ}$ to the anterior/ posterior commissure line) with the clivus removed, looking up at the attachment between the diencephalic leaf and the mesencephalic leaf of the LM. The numbers represent the following: 1) the mesencephalic leaf of LM; 2) the attachment between the diencephalic leaf and the mesencephalic leaf; 3) the pituitary stalk; 4) the oculomotor nerve; 5) the basilar artery; 6) the pons; and 7) the optic nerve. Reproduced with permission from Lü and Zhu. ${ }^{23}$ Copyright (2003) Thieme.

leaf, extends posteriorly and is divided by the oculomotor nerves that course along its upper border into a medial and lateral part. The medial part attaches along the distal basilar artery or the

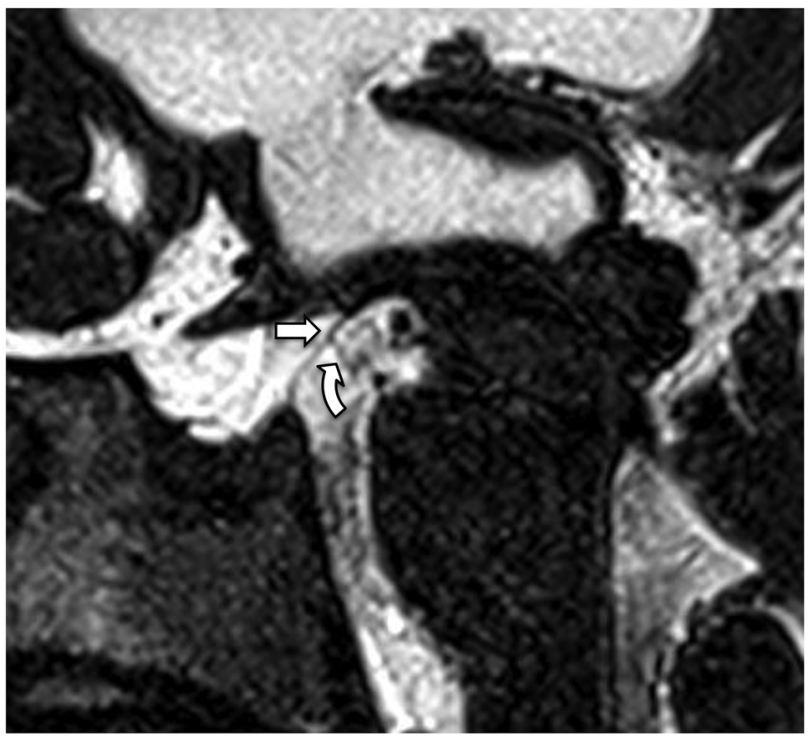

FIG 9. 3D T2 sampling perfection with application-optimized contrasts by using different flip angle evolution (SPACE sequence; Siemens) left paramedian sagittal image shows the LM with its diencephalic leaf (straight arrow) and the incomplete mesencephalic leaf (curved arrow).

pontomesencephalic junction, ${ }^{23,30,31}$ separating the interpeduncular cistern from the prepontine cistern below. It is seen less frequently on imaging than the diencephalic leaf, in keeping with 


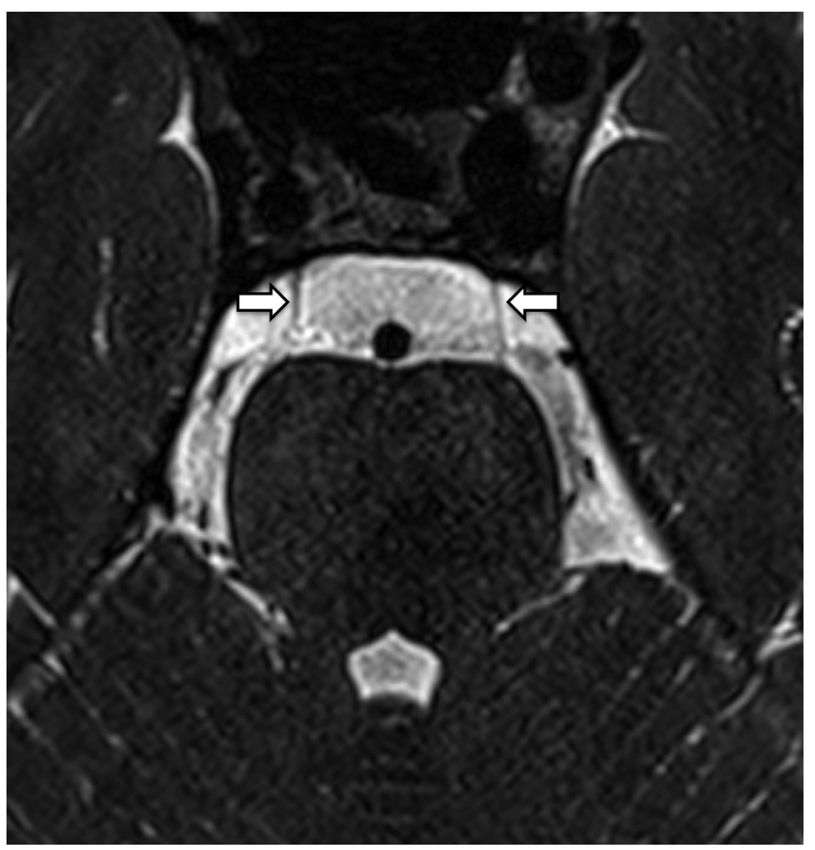

FIG 10. 3D T2 SPACE sequence axial image (0.5-mm thickness) at the level of the superior pons reveals the anterior pontine membranes bilaterally (arrows). The right anterior pontine membrane appears incomplete posteriorly.

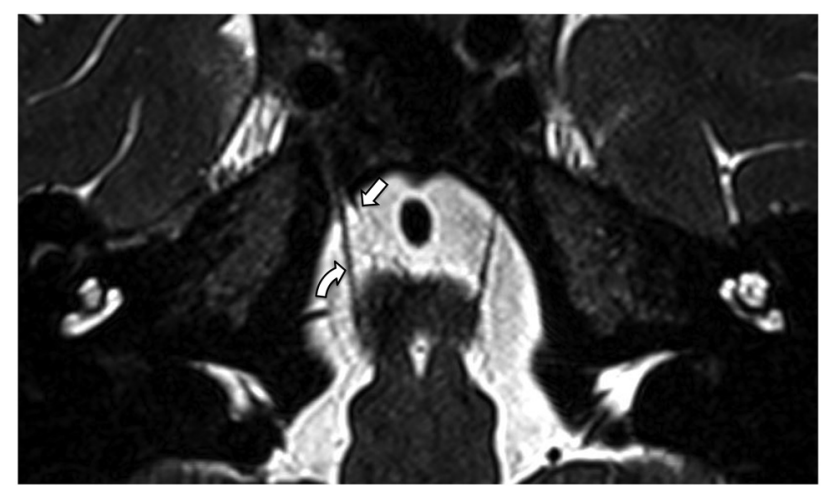

FIG 11. 3D T2 SPACE sequence with an oblique axial reformat (parallel to the abducens nerves) at the level of the lower pons shows an incomplete right anterior pontine membrane (straight arrow) medial to the right abducens nerve (curved arrow). The left anterior pontine membrane could not be seen at this level.

the microsurgical finding that the mesencephalic leaf is typically thinner, incomplete, or porous. ${ }^{19}$ The lateral part fans out to the tentorium and the mesial temporal lobes, usually located between the posterior cerebral arteries and the superior cerebellar arteries, thus separating the ambient cistern from the cerebellopontine cistern. ${ }^{26}$

The prepontine cistern is separated from the interpeduncular cistern superiorly by the mesencephalic leaf of the LM and is separated from the premedullary cistern inferiorly by the medial pontomedullary membrane, located at the level of the pontomedullary sulcus. Laterally, the prepontine cistern is separated from the cerebellopontine cisterns by the paired paramedian anterior pontine membranes, which run on both sides of the basilar artery between the pons and the clivus (Fig 10). These membranes ascend in line with the oculomotor nerves superiorly and extend inferiorly along the medial side of the abducens nerves. They become progressively thinner as they extend caudally and may disappear in the lower pons (Fig 11). ${ }^{19}$

\section{Clinical Significance}

Role in CSF Flow. The subarachnoid space, traversed by the trabeculated arachnoid membranes, is filled with CSF, an ultrafiltrate of plasma, which performs multiple vital functions including nutrient provision, waste removal, buoyancy (reducing the effective weight of the brain from $\sim 1500 \mathrm{~g}$ to $\sim 50 \mathrm{~g}$ ), ${ }^{34}$ and shock absorption. CSF is primarily produced by the choroid plexus within the ventricles at a rate of $\sim 20 \mathrm{~mL} / \mathrm{h}$, with a fairly constant total volume of $\sim 130 \mathrm{~mL}$ (in adults) spread between the ventricles $(\sim 30 \mathrm{~mL})$ and subarachnoid space surrounding the brain $(\sim 25 \mathrm{~mL})$ and cord $(\sim 75 \mathrm{~mL})^{34,35}$

The typical basic explanation of CSF flow is that after production in the choroid plexus, CSF flows through the ventricles (craniocaudal), exiting through the foramina of Luschka and Magendie into the subarachnoid space. Once within the subarachnoid space, it flows through the basal cisterns, over the convexity of the brain, and along the spinal cord where it is absorbed into the blood of the cerebral venous sinuses through arachnoid villi. ${ }^{36}$ CSF flow is presumed to be driven by a combination of a hydrostatic pressure gradient from the choroid plexus to the arachnoid villi and pulsations of the choroid plexus, with effects of both respiration and cardiac pulsations contributing to pulsatile bidirectional flow. ${ }^{37}$ Other lesser factors affecting CSF flow are posture, jugular venous pressure, physical exertion, and time of day. ${ }^{36}$

With much ongoing research in this field, the traditional view of circulatory bulk flow of CSF has increasingly been challenged. Several studies have, instead, identified and described a complex, multidirectional system with continuous fluid exchange at the blood-brain barrier and cell membranes at the CSF/interstitial fluid interface. ${ }^{35,38-40}$ Drainage and absorption of CSF are also more complex than just to the venous sinuses via the arachnoid villi, with drainage to cervical and spinal lymph nodes via the cribriform plate and spinal canal nerve roots also demonstrated. ${ }^{35}$

Recent studies have also pointed to the presence of a functional cerebral lymphatic or glymphatic system. In this system, CSF enters the Virchow-Robin perivascular spaces around arteries and arterioles in the subarachnoid space; the vessels are lined by the glia limitans, a thin layer of astrocyte foot processes rich in the aquaporin- 4 water channels. Movement of CSF across the aquaporin- 4 channels into the interstitial space of the brain is the result of convective flow (the transport of a substance by bulk flow, in which bulk flow is often the movement of fluid down a pressure gradient). ${ }^{41}$ In the interstitial space, various waste products including amyloid are dissolved in the CSF before the CSF again moves out through aquaporin- 4 channels in the VirchowRobin spaces lining the venules and veins. ${ }^{35,40,42}$

Nonetheless, a substantial volume of CSF flows from the ventricles, through the basal cisterns, and over the convexity of the brain, and this flow is affected by the anatomy of the arachnoid membranes. ${ }^{43}$ The semiconstant arachnoid membranes that form the boundaries of the interpeduncular and prepontine 

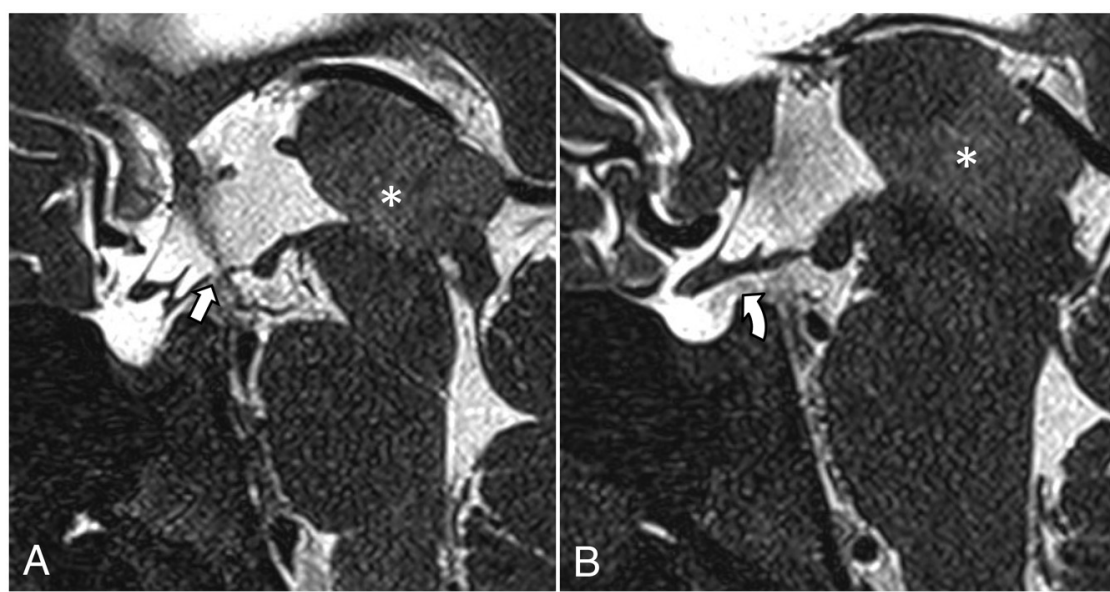

FIG 12. Postendoscopic third ventriculostomy 3D T2 SPACE midsagittal $(A)$ and left paramedian sagittal $(B)$ images in a patient with obstructive hydrocephalus at the level of the third ventricle outlet due to a left thalamic glioma with extension into the pineal gland (asterisk). A, The stoma and the CSF flow void from the third ventricle to the interpeduncular cistern are shown (arrow). $B$, The CSF flow void extends into the chiasmatic cistern (curved arrow), which suggests that the diencephalic leaf has been fenestrated or is incomplete.
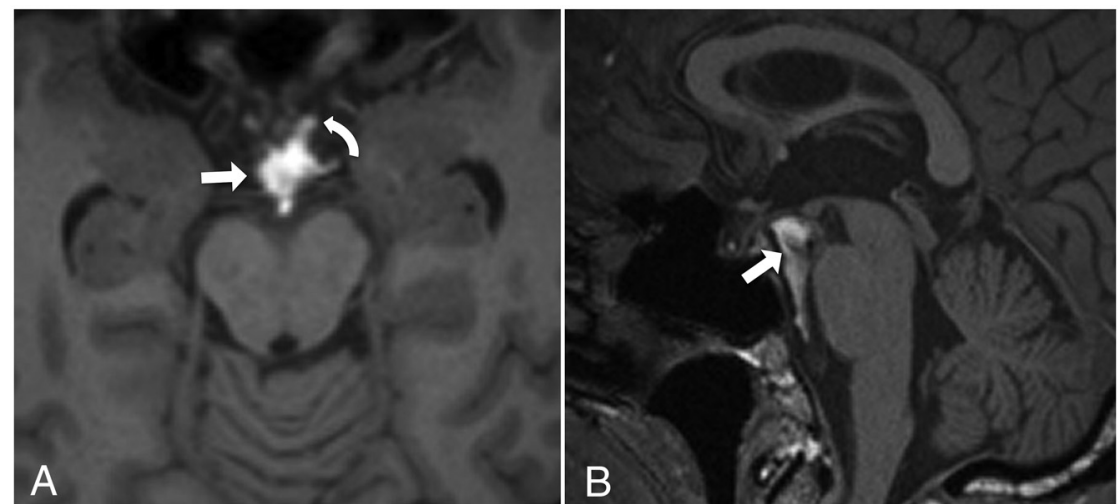

FIG 13. Axial $(A)$ and midline sagittal (B) TI MPRAGE images in a patient with nonaneurysmal perimesencephalic subarachnoid hemorrhage show that the hyperintense blood is mostly confined to the interpeduncular and prepontine cisterns (straight arrows), with only a tiny amount of blood entering the chiasmatic cistern (curved arrow).

cerebral convexities and inferiorly around the spinal cord. Absorption, as mentioned above, is via the arachnoid villi/granulations in the venous sinuses, the cribriform plate in the anterior cranial fossa, and at the spinal nerve roots.

Endoscopic Third Ventriculostomy. Endoscopic third ventriculostomy (ETV) is a surgical procedure used to treat noncommunicating hydrocephalus by creating a bypass for the CSF from the third ventricle to the basal cisterns. It involves introducing an endoscope through the brain parenchyma, usually the right frontal lobe, into the lateral ventricle. From there the endoscope is navigated through the foramen of Monro into the third ventricle. A stoma is created at the floor of the third ventricle allowing CSF to flow out of the third ventricle directly into the interpeduncular cistern. ${ }^{44}$

The importance of perforating the diencephalic leaf of the LM during ETV is well-known in the neurosurgery community. Buxton et $\mathrm{al}^{45}$ reported that the diencephalic leaf of the LM may block the flow of CSF from the third ventricle into the interpeduncular and prepontine cisterns and therefore needs to be fenestrated during the operation for a successful ETV. The CSF flow voids from the third ventricle to the interpeduncular cistern can be readily visualized on high-resolution T2weighted sequences (Fig 12).

\section{Subarachnoid Hemorrhage}

The arachnoid membranes separating the cisterns may impede the spread of

cisterns may potentially form a major conduit in which the CSF flows in a caudocranial direction in a somewhat predictable fashion. After the CSF exits the fourth ventricle through the foramina of Luschka and enters the cerebellopontine angle, it enters the prepontine cistern via apertures in the anterior pontine membranes. It continues cranially and enters the interpeduncular cistern via the openings in the medial part of the mesencephalic leaf of LM and the medial pontomesencephalic membrane. From the interpeduncular cistern, the CSF may flow either ventrally through the pores in the diencephalic leaf into the chiasmatic cistern or dorsally around the cerebral peduncles into the ambient cisterns (Fig 7). The ventral flow of CSF from the interpeduncular cistern is somewhat limited by the diencephalic leaf, as demonstrated by the arrested air column on the pneumoencephalogram in Fig 1 and the abrupt loss of CSF flow void anterior to the diencephalic leaf in Fig 4B. From here, CSF flows more slowly in the subarachnoid space superiorly over the blood to the adjacent cisterns, much as CSF flow may be obstructed (see section on "Role in CSF Flow" and Fig 7). In cases of aneurysmal subarachnoid hemorrhage, the site of the ruptured aneurysm can often be predicted by assessing the distribution of the blood on the initial unenhanced CT scan. Furthermore, nonaneurysmal perimesencephalic subarachnoid hemorrhage is often localized to the interpeduncular, ambient, and prepontine cisterns without spreading to the chiasmatic cistern (Fig 13). This localization is likely due to the presence of the diencephalic leaf of LM. ${ }^{46}$ However, due to the anatomic variations of the arachnoid membranes and the amount of extravasated blood, the extent of the perimesencephalic subarachnoid hemorrhage can be variable.

\section{Hydrocephalus}

Arachnoid membranes may be thickened secondary to inflammation or hemorrhage, and as a result, the apertures in these 

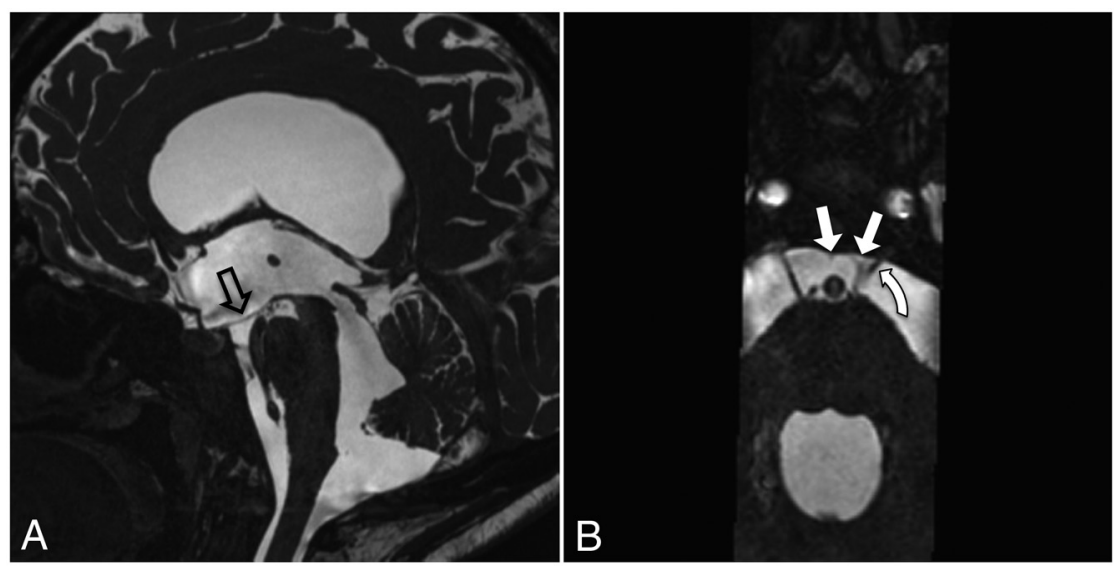

FIG 14. Midline sagittal $(A)$ and reformatted axial $(B)$ CISS sequence images in a patient with chronic extraventricular intracisternal obstructive hydrocephalus. A, Marked hydrocephalus with inferior bowing of the floor of the third ventricle (hollow arrow) and a widely patent cerebral aqueduct. $B$, The anterior pontine membranes are displaced medially (straight arrows) with the left anterior pontine membrane visibly thickened. The left abducens nerve is displaced medially (curved arrow). The displacement of the anterior pontine membranes may be due to altered CSF flow dynamics and/or tethering from other arachnoid membranes. The displacement and thickening of the membrane are likely the consequence of previous infection, inflammation, or hemorrhage, but they subsequently cause obstruction to CSF flow.

membranes may be occluded. This occlusion impedes the CSF flow within the prepontine and interpeduncular cisterns and can lead to hydrocephalus. In addition, the arachnoid membranes may be displaced due to altered CSF flow dynamics and/ or tethering from other arachnoid membranes, further impeding CSF flow. The resultant tetraventricular hydrocephalus is often interpreted as communicating hydrocephalus, but a more accurate term would be extraventricular intracisternal obstructive hydrocephalus. ${ }^{47}$ These obstructive cisternal membranes cannot be visualized on conventional MR images but can be seen on higher-resolution sequences such as the 3D-CISS sequence (Fig 14). ${ }^{32,33}$

On 3D-CISS imaging, Laitt et $\mathrm{al}^{32}$ identified "complex membranes" in the basal cisterns in 18 of 43 patients with hydrocephalus, confirmed surgically in those who underwent ETV. In patients whose ETV failed, absence of flow voids in the basal cisterns (particularly in the prepontine cistern) was usually seen and was attributed to the arrest of CSF flow by these membranes.

In their study of 134 patients with hydrocephalus, Dinçer et $\mathrm{al}^{33}$ found cisternal membranes causing obstruction in 28 cases. Most of these membranes are located in the prepontine cistern, interpeduncular cistern, or both. Seventeen of 28 cases were proved surgically during ETV, and some of these membranes were fenestrated during the operation.

In patients with tetraventricular hydrocephalus, identifying obstructive arachnoid membranes is crucial because these patients, who would have otherwise been treated with shunt insertion, can be selected for ETV. Furthermore, neurosurgeons can fenestrate these thickened membranes during ETV and, by doing so, potentially increase the success rate of the operation.

\section{CONCLUSIONS}

The arachnoid membranes play a role in both normal CSF flow dynamics and conditions characterized by abnormal CSF flow. The abnormally thickened membranes and sometimes the normal membranes can be visualized on high-resolution T2-weighted sequences. Therefore, understanding the presence and anatomy of the arachnoid membranes is becoming increasingly important for neuroradiologists.

\section{REFERENCES}

1. Killer HE, Laeng HR, Flammer J, et al. Architecture of arachnoid trabeculae, pillars, and septa in the subarachnoid space of the human optic nerve: anatomy and clinical considerations. $\mathrm{Br} \mathrm{J}$ Ophthalmol 2003;87:777-81 CrossRef Medline

2. Yasargil MG, Kasdaglis K, Jain KK, et al. Anatomical observations of the subarachnoid cisterns of the brain during surgery. J Neurosurg 1976;44:298-302 CrossRef Medline

3. Adeeb N, Deep A, Griessenauer CJ, et al. The intracranial arachnoid mater: A comprehensive review of its history, anatomy, imaging, and pathology. Childs Nerv Syst 2013;29:17-33 CrossRef Medline

4. Sanan A, van Loveren HR. The arachnoid and the myth of arachne. Neurosurgery 1999;45:152 CrossRef Medline

5. Lü J. Arachnoid membrane: the first and probably the last piece of the roadmap. Surg Radiology Anat 2015;37:127-38 CrossRef Medline

6. Connor DE, Nanda A. Bengt Liliequist: life and accomplishments of a true renaissance man. J Neurosurg 2017;126:645-49 CrossRef Medline

7. Lanska DJ. Moniz, Egaz. In: Aminoff MJ, Daroff RB, ed. Encyclopedia of the Neurological Sciences. Elsevier; 2014:92-93 CrossRef

8. Liliequist B. The anatomy of the subarachnoid cisterns. Acta Radiol 1956;46:61-71 CrossRef Medline

9. Epstein BS. The role of a transverse arachnoidal membrane within the interpeduncular cistern in the passage of Pantopaque into the cranial cavity. Radiology 1965;85:914-20 CrossRef Medline

10. Mortazavi MM, Quadri SA, Khan MA, et al. Subarachnoid trabeculae: a comprehensive review of their embryology, histology, morphology, and surgical significance. World Neurosurg 2018;111:27990 CrossRef Medline

11. O'Rahilly R, Müller F. The meninges in human development. J Neuropathol Exp Neurol 1986;45:588-608 CrossRef Medline

12. Decimo I, Fumagalli G, Berton V, et al. Meninges: from protective membrane to stem cell niche. Am J Stem Cells 2012;1:92 Medline

13. Osborn AG, Preece MT. Intracranial cysts: radiologic-pathologic correlation and imaging approach. Radiology 2006;239:650-64 CrossRef Medline

14. Logan C, Asadi H, Kok H, et al. Arachnoid cysts: common and uncommon clinical presentations and radiological features. $J$ Neuroimaging Psychiatry Neurol 2016;1:79-84 CrossRef

15. Talbert D. The embryological development of the form of the trabeculae bridging the subaracnoid space. Journal of Trauma \& Treatment 2014;3:198 CrossRef

16. Alcolado R, Weller RO, Parrish EP, et al. The cranial arachnoid and pia mater in man: anatomical and ultrastructural observations. Neuropathol Appl Neurobiol 1988;14:1-17 CrossRef Medline 
17. Vinas FC, Fandino R, Dujovny M, et al. Microsurgical anatomy of the supratentorial arachnoidal trabecular membranes and cisterns. Neurol Res 1994;16:417-24 CrossRef Medline

18. Hoeffner EG, Mukherji SK, Srinivasan A, et al. Neuroradiology back to the future: brain imaging. AJNR Am J Neuroradiol 2012;33:5-11 CrossRef Medline

19. Matsuno H, Rhoton AL, Peace D. Microsurgical anatomy of the posterior fossa cisterns. Neurosurgery 1988;23:58-80 CrossRef Medline

20. Vinas FC, Dujovny M, Fandino R, et al. Microsurgical anatomy of the arachnoidal trabecular membranes and cisterns at the level of the tentorium. Neurol Res 1996;18:305-12 CrossRef Medline

21. Vinas FC, Dujovny M, Fandino R, et al. Microsurgical anatomy of the infratentorial trabecular membranes and subarachnoid cisterns. Neurol Res 1996;18:117-25 CrossRef Medline

22. Lü J, Zhu X. Microsurgical anatomy of the interpeduncular cistern and related arachnoid membranes. J Neurosurg 2005;103:337-41 CrossRef Medline

23. Lü J, Zhu XI. Microsurgical anatomy of Liliequist's membrane. Minim Invasive Neurosurg 2003;46:149-54 CrossRef Medline

24. Lü J, Zhu XL. Characteristics of distribution and configuration of intracranial arachnoid membranes. Surg Radiol Anat 2005;27:47281 CrossRef Medline

25. Lü J, Zhu XL. Cranial arachnoid membranes: some aspects of microsurgical anatomy. Clin Anat 2007;20:502-11 CrossRef Medline

26. Qi ST, Fan J, Zhang XA, et al. Reinvestigation of the ambient cistern and its related arachnoid membranes: an anatomical study-laboratory investigation. J Neurosurg 2011;115:171- 78 CrossRef Medline

27. Zhang XA, Qi ST, Huang GL, et al. Anatomical and histological study of Liliequist's membrane: with emphasis on its nature and lateral attachments. Childs Nerv Syst 2012;28:65-72 CrossRef Medline

28. Song-Tao Q, Xi-An Z, Hao L, et al. The arachnoid sleeve enveloping the pituitary stalk: anatomical and histologic study. Neurosurgery 2010;66:585-89 CrossRef Medline

29. Inoue K, Seker A, Osawa S, et al. Microsurgical and endoscopic anatomy of the supratentorial arachnoidal membranes and cisterns. Neurosurgery 2009;65:644-64; discussion 665 CrossRef Medline

30. Kurucz P, Baksa G, Patonay L, et al. Endoscopic anatomical study of the arachnoid architecture on the base of the skull, Part II: level of the tentorium, posterior fossa and the craniovertebral junction. Innovative Neurosurg 2013;1:91-108 CrossRef

31. Volovici V, Varvari I, Dirven CM, et al. The membrane of Liliequist: a safe haven in the middle of the brain-a narrative review. Acta Neurochir (Wien) 2020;162:2235-44 CrossRef Medline

32. Laitt RD, Mallucci CL, Jaspan $\mathrm{T}$, et al. Constructive interference in steady-state 3D Fourier-transform MRI in the management of hydrocephalus and third ventriculostomy. Neuroradiology 1999;41:11723 CrossRef Medline

33. Dinçer A, Kohan S, Özek MM. Is all “communicating” hydrocephalus really communicating? Prospective study on the value of $3 \mathrm{D}$ - constructive interference in steady state sequence at 3T. AJNR Am J Neuroradiol 2009;30:1898-1906 CrossRef Medline

34. McMinn RMH, ed. Last's Anatomy: Regional and Applied. 9th ed. Elsevier; 1998

35. Bothwell SW, Janigro D, Patabendige A. Cerebrospinal fluid dynamics and intracranial pressure elevation in neurological diseases. Fluids Barriers CNS 2019;16:9 CrossRef Medline

36. Sakka L, Coll G, Chazal J. Anatomy and physiology of cerebrospinal fluid. Eur Ann Otorhinolaryngol Head Neck Dis 2011;128:309-16 CrossRef Medline

37. Dreha-Kulaczewski S, Konopka M, Joseph AA, et al. Respiration and the watershed of spinal CSF flow in humans. Sci Rep 2018;8:5594 CrossRef Medline

38. Chikly B, Quaghebeur J. Reassessing cerebrospinal fluid (CSF) hydrodynamics: a literature review presenting a novel hypothesis for CSF physiology. J Bodyw Mov Ther 2013;17:344-54 CrossRef Medline

39. Brinker T, Stopa E, Morrison J, et al. A new look at cerebrospinal fluid circulation. Fluids Barriers CNS 2014;11:10 CrossRef Medline

40. Iliff JJ, Nedergaard M. Is there a cerebral lymphatic system? Stroke 2013;44:S93-95 CrossRef Medline

41. Ray L, Iliff JJ, Heys JJ. Analysis of convective and diffusive transport in the brain interstitium. Fluids Barriers CNS 2019;16:6 CrossRef Medline

42. Bradley WG. CSF flow in the brain in the context of normal pressure hydrocephalus. AJNR Am J Neuroradiol 2015;36:83138 CrossRef Medline

43. Brodbelt A, Stoodley M. CSF pathways: a review. $\mathrm{Br} J$ Neurosurg 2007;21:510-20 CrossRef Medline

44. Hellwig D, Grotenhuis JA, Tirakotai W, et al. Endoscopic third ventriculostomy for obstructive hydrocephalus. Neurosurg Rev 2005;28:1 CrossRef Medline

45. Buxton N, Vloeberghs M, Punt J. Liliequist's membrane in minimally invasive endoscopic neurosurgery. Clin Anat 1998;11:187-90

46. Schwartz TH, Solomon RA. Perimesencephalic nonaneurysmal subarachnoid hemorrhage: review of the literature. Neurosurgery 1996;39:433-40 CrossRef Medline

47. Kehler U, Gliemroth J. Extraventricular intracisternal obstructive hydrocephalus: a hypothesis to explain successful 3rd ventriculostomy in communicating hydrocephalus. Pediatr Neurosurg 2003;38:98-101 CrossRef Medline

48. Saboori P. Subarachnoid space trabeculae architecture. Clin Anat 2021;34:40-50 CrossRef Medline

49. Cleary JO, Yoo PE, Moffat BA, et al. See it, slice it, learn it: combined ultra-high-field MRI and high-resolution CT for an open source virtual anatomy resource. In: Proceedings of the Annual Meeting and Exhibition of the International Society for Magnetic Resonance in Medicine, April 22-27, 2017; Honolulu, Hawaii 